3. Eta neither prevents nor treats $U$.

4. Topical NSAIDs and G can hardly be recommended as a reliable means for treatment of $U$ without TNFi and MTX.

5. Systemic NSAIDs neither prevent nor treat JIA-associated U.

REFERENCES:

[1] Constantin T, Foeldvari I, Anton J, et al. Consensus-based recommendations for the management of uveitis associated with juvenile idiopathic arthritis: the SHARE initiative Ann Rheum Dis 2018;77:1107-1117

[2] Angeles-Han ST, Ringold S, Beukelman T, Lovell D et al., 2018 American College of Rheumatology/Arthritis Foundation Guideline for the Screening, Monitoring, and Treatment of Juvenile Idiopathic Arthritis-Associated Uveitis. Arthritis Care Res (Hoboken). 2019 June; 71(6): 703-716

Disclosure of Interests: None declared

DOI: 10.1136/annrheumdis-2021-eular.3327

\section{POS1325 \\ COMPARISON OF THREE DIFFERENT ALGORITHMS FOR THE TREATMENT OF CHILDREN WITH POLYARTICULAR JIA: THE FIRST YEAR AFTER DIAGNOSIS}

K. Minden ${ }^{1,2}$, T. Schwarz ${ }^{3}$, F. Dressler ${ }^{4}$, I. Foeldvari ${ }^{5}$, J. P. Haas ${ }^{6}$, G. Horneff ${ }^{7}$, T. Hospach ${ }^{8}$, J. Kümmerle-Deschner ${ }^{9}$, K. Moenkemoeller ${ }^{10}$ F. Weller-Heinemann ${ }^{11}$, K. Tenbrock ${ }^{12}$, M. Niewerth ${ }^{1}$, C. Sengler ${ }^{1}$, D. Foell ${ }^{13}$, J. Klotsche ${ }^{1} .{ }^{1}$ Deutsches Rheuma-Forschungszentrum Berlin, Epidemiology, Berlin, Germany; ${ }^{2}$ Charité Universitätsmedizin Berlin, Paediatric Rheumatology, Berlin, Germany; ${ }^{3}$ St-Josef-Stift Sendenhorst, Paediatric Rheumatology, Sendenhorst, Germany; ${ }^{4} \mathrm{MHH}$, Kinderklinik, Hannover, Germany; ${ }^{5}$ Hamburg Center for Pediatric and Adolescent Rheumatology, Pediatric and Adolescent Rheumatology, Hamburg, Germany; ${ }^{6}$ Deutsches Zentrum für Kinder- und Jugendrheumatologie, Kinder- und Jugendrheumatologie, Garmisch-Partenkirchen, Germany; ${ }^{7}$ Asklepios Kinderklinik, Paediatric Rheumatology, St. Augustin, Germany; ${ }^{8}$ Olgahospital Stuttgart, Paediatric Rheumatology, Stuttgart, Germany; ${ }^{9}$ Universitätskinderklinik Tübingen, Paediatric Rheumatology, Tübingen,; ${ }^{10}$ Kinderkrankenhaus Amsterdamer Straße, Paediatric Rheumatology, Köln, Germany; ${ }^{11}$ Klinikum Bremen Mitte, Prof. Hess Kinderklinik, Bremen, Germany; ${ }^{12}$ Universitätsklinikum Aachen, Kinder- und Jugendmedizin, Aachen, Germany; ${ }^{13}$ Universitätsklinikum Münster, Klinik für Pädiatrische Rheumatologie und Immunologie, Münster, Germany

Background: Various treatment strategies are used for children with newly diagnosed polyarticular JIA. MTX is usually prescribed, sometimes in combination with high-dose intravenous glucocorticoid pulses (HDGC) or multiple intra-articular GC injections (IAGC). These different approaches were considered in the German consensus-based treatment protocols for polyarticular $\mathrm{JIA}^{1}$, they were also the leading therapies in patients with rheumatoid factor-negative polyarthritis (RF- PA) included in the JIA inception cohort ICON.

Objectives: To compare the effectiveness of three different treatment strategies in nearly DMARD-naïve patients with RF- PA.

Methods: Patients with RF- PA who were included in the ICON cohort and received one of the following treatments within the first three months were considered for the analysis: Group 1: MTX + IAGC in >4 joints, Group 2: MTX + HDGC, Group 3: MTX, no IAGC in $>4$ joints, no HDGC. Propensity score-adjusted group differences in outcomes after one and two years were analysed by linear and logistic regression analyses.

Results: The analysis included data from 150 patients (79\% female, mean age $6.7 \pm 4.8$ years) enrolled in ICON $1.6 \pm 1.9$ months after the diagnosis of RF- PA, of whom 52 were in Group 1, 54 in Group 2 and 44 in Group 3. Disease activity did not differ significantly between the groups at treatment start (cJADAS-10 $16.7 \pm 4.7,15.8 \pm 5.7,15.9 \pm 6.5$, respectively).

Of the total group, at 1- and 2-year follow-up (FU), 60.9\%/60.1\% and $52.3 \% / 58.8 \%$ of patients had inactive disease (cJADAS $\leq 1 /$ Wallace criteria $^{2}$ ), $21.3 \%$ and $35.6 \%$ were in remission off drug $^{2}$, and mean cJADAS-10 scores were $2.6 \pm 3.9$ and $3.0 \pm 3.5$, respectively. $60.5 \%$ and $67.0 \%$ had no functional limitations $(\mathrm{CHAQ}=0)$.

Patients in Group 1 more often had an inactive disease (according to Wallace ${ }^{2}$ ) at the 1-year FU and tended to have inactive disease more often at 2-year FU than patients in Group $3(78.1 \%$ vs. $45.2 \%, p=0.025 ; 73.3$ vs. $49.1 \%, p=0.075$, respectively). Group 2 patients (inactive disease in $56.1 \%$ and $53.4 \%$ at 1 and 2-year FU) did not differ significantly from either Group 1 or Group 3. In addition, Group 1 patients had a significantly better quality of life than patients of Group 2 at the 2-year FU (mean PedsQL 4.0 total score $90.4 \pm 9.3$ vs. $83.8 \pm 11.2, p=0.031$ ). At that time, Group 3 patients had a mean PedsQL 4.0 total score of $85.0 \pm 14.6$, which was not significantly different from either Group 1 or 2.

On the other hand, Group 1 patients tended to develop new uveitis more frequently within the first two years of treatment than patients in Groups 2 and
$3(13 \%$ vs. $2.2 \%$ and $3.6 \%, p=0.101$ and 0.131 , respectively). At the 2 -year FU, patients in Group 1 also had a significantly lower mean height SDS than patients of Group $3(-0.3 \pm 1.1$ vs. $0.2 \pm 1.1, p=0.038)$. Mean height SDS was lowest $(-0.5 \pm 0.8)$ in patients in Group 2 and significantly lower than in Group 3 (0.019). Mean body mass index SDS also differed significantly between the groups at 2-year follow-up. The mean BMI SDS was highest in Group 1 patients $(0.2 \pm 0.8)$, differing significantly from Group $2(-0.3 \pm 0.7, p=0.014)$ and Group 3 $(-0.4 \pm 1.1, \mathrm{p}=0.023)$.

There were no significant differences in inactive disease (according to cJADAS) and functional status (CHAQ) between the three groups at 1- and 2-year FU. Over time, treatments were very different in the three groups. In Group 3, biologics were used significantly more often over time than in group $1(54.0 \%$ vs. $18.3 \%, p=0.014)$, and Group 2 patients received bDMARDs in $36.1 \%$.

Conclusion: While patients with numerous early joint injections seem to achieve inactive disease more frequently and earlier, they have a slightly smaller body height and tend to develop uveitis slightly more often than patients with more intensive DMARD therapy. However, the differences are small between the groups. Further comparative effectiveness studies with higher patient numbers are needed to identify particularly effective and safe treatment strategies.

\section{REFERENCES:}

[1] Horneff et al. Pediatric Rheumatology 2017;15:78.

[2] Wallace et al. Arthritis Care Res (Hoboken) 2011;63:929-36.

Acknowledgements: The ICON study is funded by a research grant of the Federal ministry of education and research (BMBF, FKZ 01ER0812, FKZ 01ER1504A-C)

Disclosure of Interests: Kirsten Minden Speakers bureau: Pfizer, Abbvie, Consultant of: Novartis, Tobias Schwarz: None declared, Frank Dressler: None declared, Ivan Foeldvari Consultant of: Gilead, Novartis, Pfizer, Hexal, BMS Sanofi, MEDAC, Johannes-Peter Haas: None declared, Gerd Horneff Speakers bureau: Pfizer, Consultant of: Novartis, Toni Hospach Consultant of: Novartis Jasmin Kümmerle-Deschner: None declared, Kirsten Moenkemoeller: None declared, Frank Weller-Heinemann Speakers bureau: Pfizer, AbbVie, SOBI, Roche, Novartis, Klaus Tenbrock: None declared, Martina Niewerth: None declared, Claudia Sengler: None declared, Dirk Foell: None declared, Jens Klotsche: None declared

DOI: 10.1136/annrheumdis-2021-eular.3448

\section{POS1326 FAMILIAL PERIODIC FEVER, APHTHOUS STOMATITIS, PHARYNGITIS AND ADENITIS (PFAPA)SYNDROME; IS IT A SEPARATE DISEASE?}

Y. Butbul ${ }^{1} .{ }^{1} 1$ The Ruth and Bruce Rappaport Faculty of Medicine, Technion Israel Institute of Technology, Haifa, Israel, Pediatric Rheumatology unit, Haifa, Israel

Background: Periodic fever, aphthous stomatitis, pharyngitis, and adenitis syndrome (PFAPA) is the most common periodic fever syndrome in the pediatric population. Unlike other periodic fever syndromes, the pathogenesis and genetics of PFAPA is unknown. Until recently, PFAPA was believed to be a sporadic disease, yet family clustering has been widely observed and current research indicates that heredity is likely.

Objectives: To identify demographic and clinical differences between patients with PFAPA who have a positive family history $(\mathrm{FH}+)$ compared to those with PFAPA with no family history (FH-) that can reveal if heritable and sporadic subtypes of this disorder exist.

Methods: In a database comprising demographic and clinical data of 273 pediatric PFAPA patients treated at two tertiary centers in Israel, 31(14.3\%) of patients were PFAPA $\mathrm{FH}+$. Data from patients with $\mathrm{FH}+$ for PFAPA was compared to data from those with $\mathrm{FH}$ - of the disorder. Furthermore, family members (FMs) of those with $\mathrm{FH}+$ were contacted via telephone for more demography and clinical details.

Results: $\mathrm{FH}+$ group had more headaches (32\% vs. $2 \% ; \mathrm{p}=0.016)$, myalgia (56\% vs. $19 \% ; p=0.001$ ), higher carrier frequency of M694V mutation (54\% vs. $25 \% ; p=0.053)$, greater family history of FMF $(30 \%$ vs. $15 \% ; p=0.096)$ and better outcomes with colchicine ( $82 \%$ vs. $52 \%$; $p=0.096)$ compared to those with $\mathrm{FH}$-. FMs displayed almost identical characteristics to the $\mathrm{FH}+$ group except for greater arthralgia during flares (64\% vs. $23 \% ; p=0.008)$ and compared to the $\mathrm{FH}$ - group, more oral aphthae ( $68 \%$ vs. $43 \% ; \mathrm{p}=0.002)$, myalgia/arthralgia (64\% vs. $19 \% / 16 \% ; p<0.0001)$, and higher rates of $\mathrm{FH}$ of $\mathrm{FMF}(45 \%$ vs. $15 \%$; $\mathrm{p}=0.003)$.

Conclusion: Our findings suggest that $\mathrm{FH}+$ had probably different subset of disease with higher frequency of family history of FMF arthralgia, myalgia and better response to colchicine. Colchicine prophylaxis for PFAPA should be considered in $\mathrm{FH}+$

Disclosure of Interests: None declared

DOI: 10.1136/annrheumdis-2021-eular.3458 